\title{
Development of Simple Software for Irrigation Scheduling of a Crop
}

\author{
C.Sivapragasam, S.Ponmalar
}

\begin{abstract}
Availability of fresh water is becoming scare throughout the world and is of great concern to everyone. It is believed that scarcity of water will affect the agricultural production significantly. While alternative approaches for saving water is necessary, it is equally important to use the available water judiciously. For a given crop, during its entire growth period, the water requirements vary. If estimation can be made on the quantity of water required for the growth of a plant and the frequency interval of watering the crop, it is possible for the farmers to judiciously use water without affecting the quality of the production. This project will design a software system wherein for a given crop and location of the land, the farmers will be able to estimate the water requirement and frequency of watering. And this system also incorporates the facility for forecasting the temperature during the crop growth period.
\end{abstract}

Keywords : crop water requirement, evapotranspiration, temperature forecast, irrigation scheduling.

\section{INTRODUCTION}

The pressure of freshwater scarcity is increasingly felt throughout the world. India consumes about $80 \%$ of its freshwater for agriculture. Most farmers in India still follow flood irrigation resulting in lot of water loss $[1,2]$. One of the easiest way to address this issue is to help the farmers know the exact amount of water a crop needs during different stages of its growth for a given geographical, climatic and soil condition. In the recent past, new technological approaches are being considered for accurate estimation of actual crop evapotranspiration. For instance, [3] used large-aperture scintillometer and eddy covariance instruments and reported that the actual evapotranspiration thus obtained is lesser by $35 \%$ of the crop evapotranspiration obtained using Penman-Monteith method for an experimental farm at Italy. Their results corroborate the previous findings by researcher [4] who after studying many methods including FAO Penman-Monteith, Penman, Blaney - Criddle, Hargreaves etc reported that the estimated evapotranspiration by these methods are on the higher side when compared to those obtained using instruments like lysimeter.

Despite the above discussed fact, the estimation of evapotranspiration using the theoretical methods is still widely used all over the world. The estimation by any of these methods will certainly be much lower than the water used in flood irrigation method. Besides, being economically challenged, the farmers in developing countries are not in a

Revised Manuscript Received on December 05, 2019.

* Correspondence Author

Dr.C.Sivapragasam*, Center of Water Technology, Department of Civil Engineering, Krishnankoil, India. Email: sivapragasam25@gmail.com

Ms. S.Ponmalar, Technical Officer, Kalasalingam Academy of Research and Education, Krishnankovil, India. Email:csmalar007@gmail.com position to adopt highly instrumental based methods even at the cost of accuracy. Hence, implementing one of the theoretical methods through promotion of technology in simpler level at the rural region of the country can be highly effective in saving freshwater without affecting the agricultural yield. In simple words, this work recommends practice of precision agriculture in its simplest form which uses information technology to develop software that can estimate the minimum water required to fulfil the evapotranspiration needs of the crop and ensure maximum productivity.

The CROPWAT software is one of the free download software for irrigation scheduling which uses Penman equation for estimation of evapotranspiration. However, this software is highly memory intensive and data intensive, and cannot be easily converted to an App to be used by the farmers. Hence, there is a need to develop simpler software which can give irrigation scheduling details with lesser meteorological information without adversely affecting the accuracy. Of many methods available, in this study, the estimation of evapotranspiration is implemented in the developed software using Blaney Criddle method [2, 3] as a default option primarily because it uses minimum number of meteorological parameters and is widely used by many engineers. The proposed software also incorporates the facility for forecasting the temperature during the crop growth period based on the historical mean temperature time series. Genetic Programming (GP) is used to develop mathematical model for forecasting the temperature. In order to doubly ensure the applicability of this empirical method, it is proposed to conduct pilot scale study growing the same crop in a limited area with the irrigation water requirement as estimated using the software.

\section{MATERIALS AND METHODS}

Fig.1 shows the flowchart of the various inputs and the output to the developed software tool. For a given crop, it is necessary to know the growth stages classified into four major categories namely initial stage, crop development stage, mid season stage and late season stage. The crop coefficient corresponding to a given growth stage is taken from standard references. The user is given flexibility to edit the crop growth stages as well as the crop coefficients given as default values for a selected crop. 


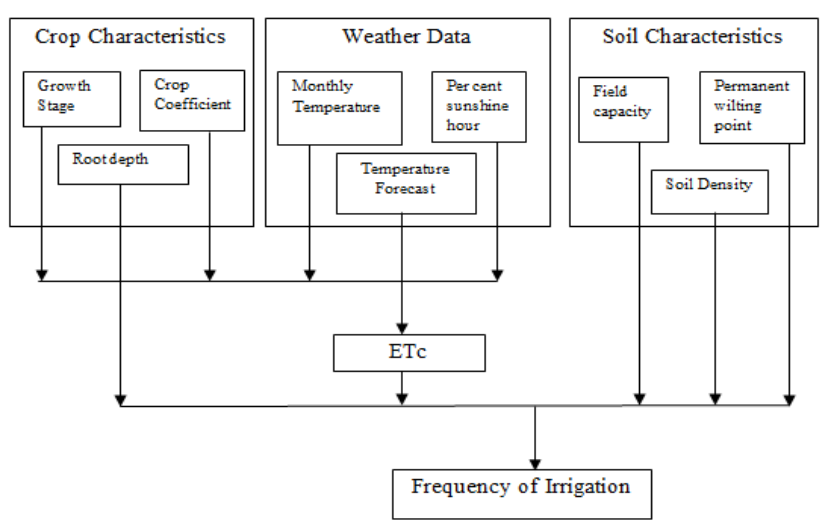

Fig. 1. Flowchart indicating inputs and outputs for the software

For the application of Blaney Criddle method, the weather information required is the mean monthly temperature and the percent sunshine hour for given latitude. Users can edit the monthly temperature for different months during the crop growth stage. Choice is given to the users to prefer forecasting of temperature if required.

The temperature forecast model is evolved using GP which is an evolutionary algorithm build on mimicking the Darwin's theory of natural selection and survival of the fittest. The GP algorithm generates initial set of equations through random combination of terminal set (constants and variables governing the process) and functional set (arithmetic operators and mathematical functions). This initial set of equations are further refined with the passage of 'generations' using crossover or mutation operators. Details can be referred to in [5]. In this study, the GP model uses the temperature of current month and that of the previous month to forecast the temperature of the next month. The GP evolved model for the temperature forecast is given in "(1)".

$T_{2}=\left[\frac{-T_{1}}{T_{0}^{2}}+\frac{9.08}{T_{0}}\right]^{2}+T_{1}$

where $T_{1}$ is previous month temperature, $T_{0}$ is the current month temperature and $T_{2}$ is the forecasted temperature for the next month. This forecasted temperature will be the current month temperature when the software runs in iteration to forecast the future temperatures.

With these inputs, the use of Blaney Criddle equation as given in "(2)" will yield the monthly evapotranspiration for the crop.

$$
E T_{c}=2.54 k_{c} \frac{\sum P_{h} \overline{T_{f}}}{100}
$$

where $\mathrm{ETc}=$ evapotranspiration in a crop season in $\mathrm{cm}, \mathrm{k}_{\mathrm{c}}=$ an empirical coefficient which depends on the type of crop and the stage of growth, $\mathrm{P}_{\mathrm{h}}=$ monthly percent of annual day-time hours which is a function of latitude of a place (and obtained from standard available charts) and $T_{f}=$ mean monthly temperature in ${ }^{\circ} \mathrm{F}$.
For the estimation of frequency of irrigation, it required to know the water storage capacity of the soil which depends on the soil type as well as the crop root depth. The user can input the field capacity and permanent wilting point in the software tool. The default option will consider $80 \%$ of the available moisture to be the optimal moisture. Irrigation is to be planned before this stage. Frequency of irrigation is estimated by dividing the available soil moisture depletion and daily water use.

The software tool is implemented with Windows 7 as the operating system with ASP.NET with $\mathrm{C \#}$ as the front end and SQL server as the back end. The same can be developed as a mobile app to be used by the farmers directly

\section{RESULT AND DISCUSSION}

The flow steps shown in Fig. 1 is consolidated into the software by means of three major modules namely estimation of water requirement (evapotranspiration) module, temperature forecast module and the frequency of irrigation module. Fig. 2 to 6 illustrates these modules from the users' point of view.

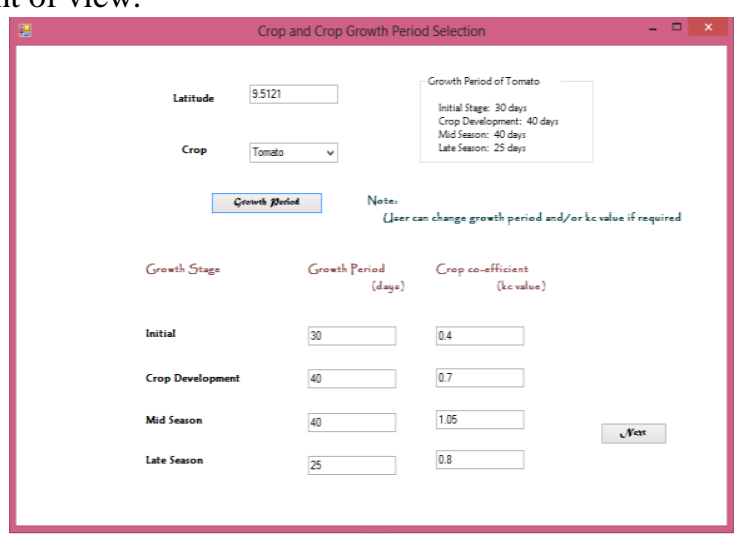

Fig. 2.Flowchart indicating inputs and outputs for the software

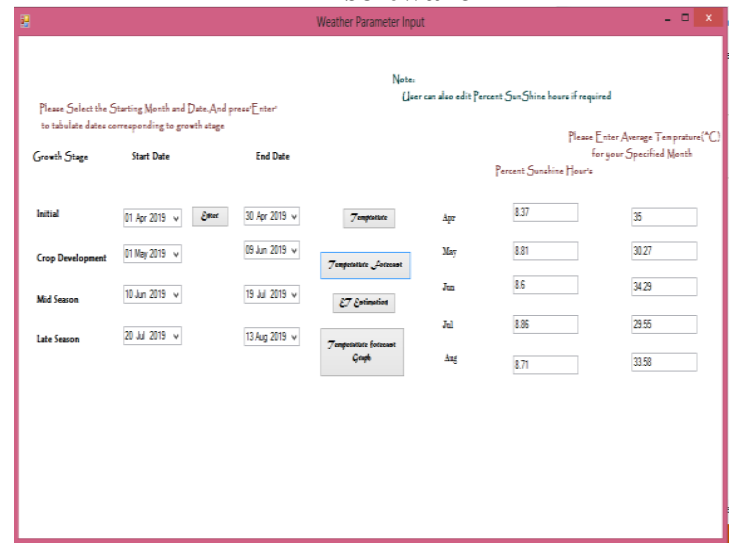

Fig. 3.Fig. 3.Screen showing weather parameter inputs 


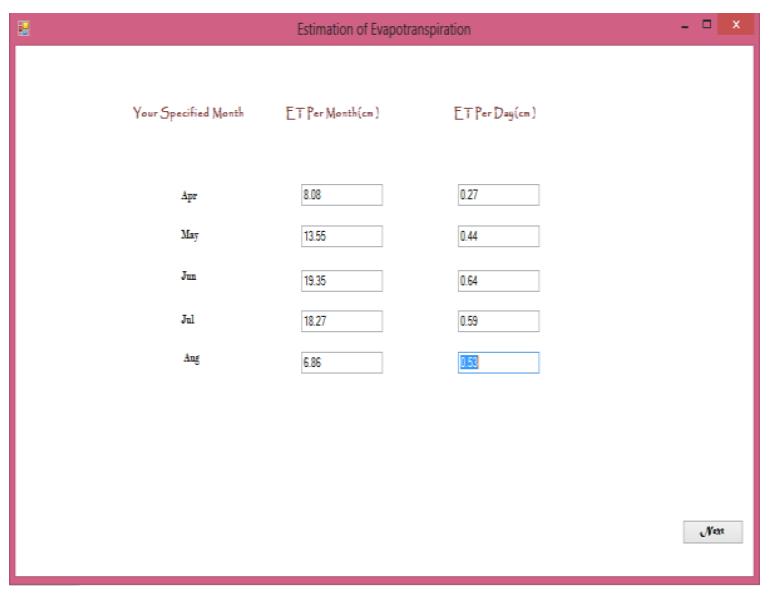

Fig. 4.Estimated ETc per month and per day

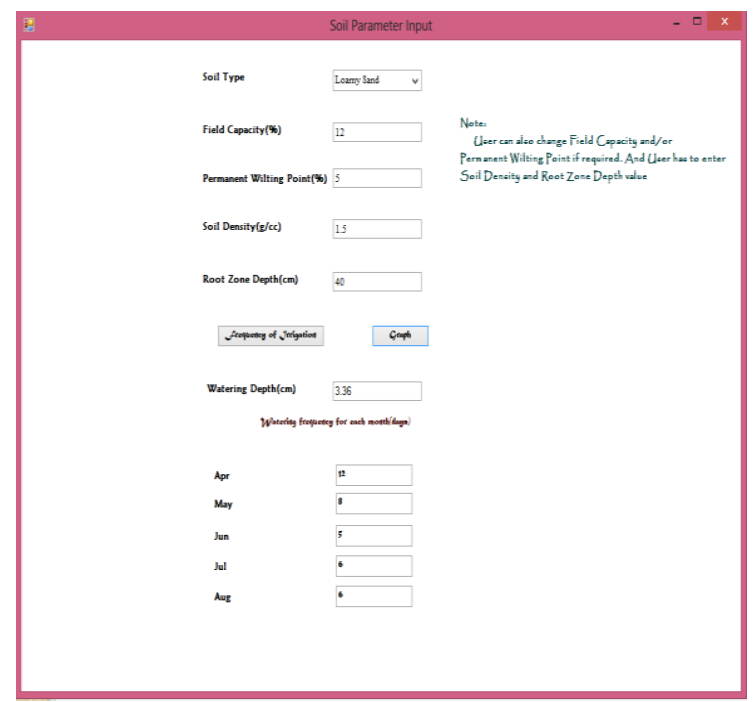

Fig. 5.Screen showing soil parameters input

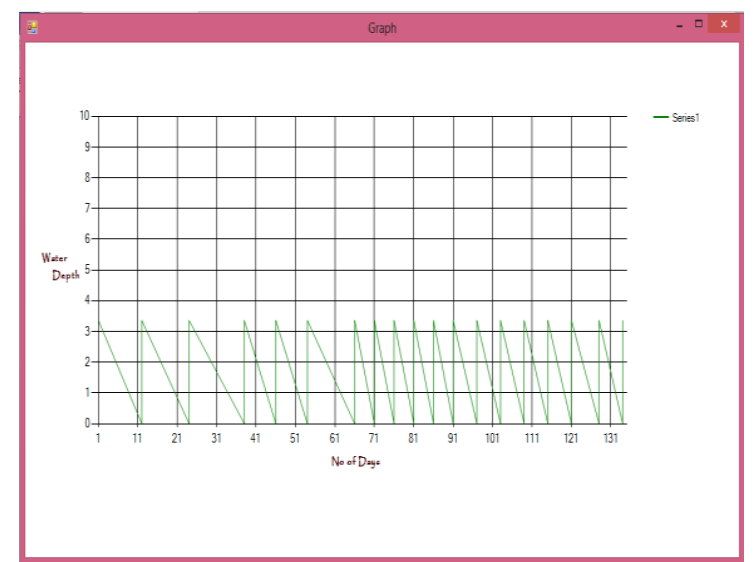

Fig. 6.Screen showing the frequency of irrigation

The software gives flexibility to the users to choose the crop growth period (in number of days) for a given crop. Once the starting date of the crop is decided by the user, the software automatically tabulates the exact dates for the different stages of crop growth. By default, the software will allow the user to enter the average monthly temperature for the different months associated with the growth of a given crop. If the user prefers to forecast the temperature, that is also done. However, the time series data should contain atleast the current month and the previous month temperature. The estimated value of ETc is displayed to the user both per month as well as per day. Table 1 shows the predicted temperature and the estimated ETc for both actual temperature and forecasted temperature.

Table- II: COMPARISON OF ET $_{\mathrm{C}}$ WITH ACTUAL AND FORECAST TEMPERATURE

\begin{tabular}{|l|l|l|l|l|}
\hline Month & $\begin{array}{l}\text { Actual } \\
\text { Temperatur } \\
\text { e(Celsius) }\end{array}$ & $\begin{array}{l}\text { Temperatur } \\
\text { e forecast } \\
\text { (Celsius) }\end{array}$ & $\begin{array}{l}\text { ETc in cm } \\
\text { (actual } \\
\text { temp })\end{array}$ & $\begin{array}{l}\text { ETc in cm } \\
\text { (Temperatur } \\
\text { e forecast })\end{array}$ \\
\hline Apr & 35 & 35 & 8.08 & 8.08 \\
\hline May & 32 & 31 & 14.04 & 13.55 \\
\hline Jun & 30 & 33 & 17.75 & 19.35 \\
\hline Jul & 27 & 29 & 17.29 & 18.27 \\
\hline Aug & 26 & 34 & 5.85 & 6.86 \\
\hline
\end{tabular}

The soil parameters (field capacity, permanent wilting point and root zone depth) are displayed as default values for the selected soil but the user has the flexibility to change the same, if required. Based on the ETc for a given month and the storage capacity of the soil is estimated, the frequency of irrigation is decided. In this study, it is assumed that there is no rainfall or the ETc represents the net irrigation demand after removing the rainfall component.

The proposed software system is implemented for a real time study at the experimental scale for maize crop. The crop was watered as per the estimation made from the software. Fig. 7 shows the planting and growth of the crop over different days of its growth period.

\section{CONCLUSION}

The following conclusions are arrived at based on the study carried out:

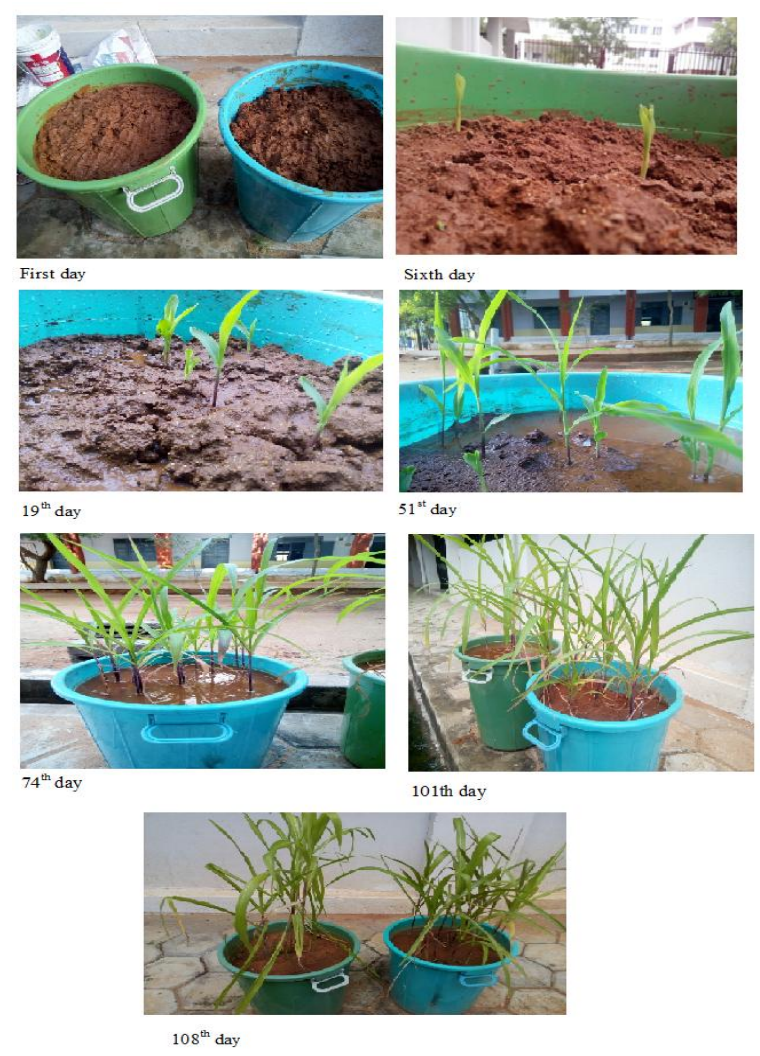

Fig.7. Stages of crop growth

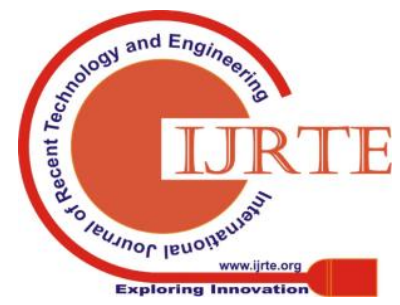


a) Blaney-Criddle equation gives reasonably accurate estimation of ETc for the region under study and hence can be recommended to be used as an alternative to more cumbersome Penman-Monteith equation.

b) The Genetic Programming is a promising tool to develop mathematical models for temperature forecast. As an alternative, when implementing this as a mobile app, temperature forecasted by certain weather predictor can be used, and avoid receiving inputs by the farmers.

c) The software developed is economical and east to use by the farmers when compared to the other software available.

\section{ACKNOWLEDGMENT}

The authors' also wish to express their gratitude to Ms. Sumila, Ms. Farzana and Ms. Keerthi of Department of Civil Engineering for their support to initiate the work at the first level and for the help rendered in the lab scale experimental study..

\section{REFERENCES}

1. Dhawan, Vibha. Water and Agriculture in India: Background Paper for the South Asia Expert Panel: During the Global forum for Food and Agriculture . OAV - German Asia-Pacific Business Association within the Frame of the Bilateral Cooperation Project on the Development of International Cooperation with Asia, Co-Funded by the Federal Ministry of Food and Agriculture (BMEL). 2017. Date Accessed: June 20, 2018.

2. G.L.Asawa, "Irrigation and water resources engineering", New age International Publishers, 2005.

3. R. Ragab, J.G. Evans , A. Battilani, "Towards Accurate Estimation of Crop Water Requirement without the Crop Coefficient Kc: New Approach Using Modern Technologies”. Irrigation and Drainage. Vol.66(4), 2017, pp.469-477.

4. P.S.Kashyap, R.K. Panda, "Evaluation of evapotranspiration estimation methods and development of crop-coefficients for potato crop in sub-humid region", Agricultural Water Management Vol.50: 2001, pp 9-25.

5. J.R.Koza, "Genetic Programming: on the programming of computers by natural selection", $1^{\text {st }}$ edn. MIT Press, Cambridge, MA , 1992.

\section{AUTHORS PROFILE}

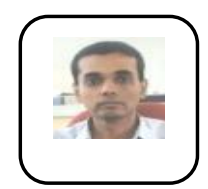

Dr. C.Sivapragasam has completed his graduation and post-graduation from IIT-Roorkee and IIT-Delhi respectively. He completed his $\mathrm{PhD}$ from NUS, Singapore. He has 2 years of industry experience and more than 17 years of teaching experience. He has completed 3 sponsored research projects from various funding agencies and published more than 70 papers in peer reviewed journals and conferences..

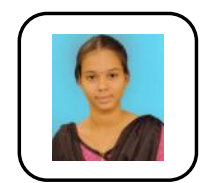

S.Ponmalar has completed her B.Sc (Computer Science) from Arulmigu Kalasalingam College of Arts and Science and Masters of Computer Applications from Ayya Nadar Janaki Ammal College. She has a keen interest to develop software applications for engineering problems. 